KLEINE, P.; TRIVINHO-STRIXINO,

S. Chironomidae and other aquatic

macroinvertebrates of a first order stream:

community response after habitat fragmentation. Acta Limnol. Bras., v.17,p. 81-90, 2005.

MACCAFFERTY, W.P. Aquatic Entomology. Chave de identificação das principais ordens e famílias de insetos aquáticos. Boston: Jones and Bartlett Publishers, INC. 1981

MAITLAND, P.S. The distribution of zoobenthos and sediments in Loch Leven, Kinross, Scotland. Archiv fur Hydrobiologie. v. 5, n.85, p. 98-125, jan. 1979.

METCALF, L., EDDY, H.P. Tratamiento y depuración de las aguas residualis, Madrid, Editora Labor, 837p. 1977.

NEGREIROS, S. CETESB conclui inventário e prepara plano de ação, Saneamento Ambiental, $\mathrm{n}$. 46, p. 30-34, 1997

OMETO, J.P.H.B.; MARTINELLI, L.A.;

BALLISTER, M.V.; GESSNE, R A.; KRISCHE A.V. and VICTORIA, R.L. The effects of land use on water chemistry and macroinvertebrates rates in two streams of the Piracicaba river basin South-east Brazil. Freshwater Biol., 44, p.327337,2000

PELÁEZ-RODRÍGUEZ, M. Avaliação da qualidade da água da Bacia do Alto JacaréGuaçú - SP (Ribeirão do Feijão e Rio

Monjolinho) através de varáveis Físicas,

Químicas e Biológicas.144f. Tese (Doutorado) -Universidade de São Paulo, 2001.

POSSETI, R.B. Avaliação do impacto da estação de tratamento de esgoto (ETE) do município de Araraquara - SP, no manancia Ribeirão das Cruzes, pela utilização dos macroinvertebrados aquáticos como bioindicadores. Dissertação (Mestrado) USP, São Carlos. 2015

RICHARDS, C.; JOHNSON, L.B.; HOST, G.E. Landscape-scale influences on stream habitas and biota. Can. J. Fish. Aquat. Sci. v.53 p. 295-311, 1996.

ROQUE, F.O.; CORBI, J.J. AND TRIVINHOSTRIXINO, S. Considerações sobre a utilização de larvas de Chironomidae (Diptera) na avaliação da qualidade da água de Córregos do Estado de São Paulo. In: ESPINDOLA, E.L.G.;

PASCHOAL C.M.R.B., ROCHA O; BOHRER M.B.C. ;Neto A.L.O (Ed.). Ecotoxicologia: perspectivas para o século XXI. São Carlos:Rima Editora, 2000. p. 115-126. 2000.

ROSENBERG, D.M.; RESH, V.H.

Freshwater biomonitoring and benthic

macroinvertebrates. New York : Chapman \& Hall, 1993. 488p.

TRIVINHO-STRIXINO, S.; STRIXINO, G.

Larvas de Chironomidae (Díptera) do Estado de São Paulo: . Guia de identificação diagnose dos gêneros. São Carlos: PPG- ERN/ UFSCar, 1995. 229p

OLIVEIRA, Alessandra Rosa de. - Especialista em Língua Portuguesa: Redação e Oratória, pelo Centro Universitário Barão de Mauá. Graduada em Letras e Psicologia. Docente e Psicóloga na Prefeitura Municipal de Guariba/SP.

LOPES, Mario Marcos. - Mestre em Desenvolvimento Regional e Meio Ambiente pela Universidade de Araraquara. Especialista na área educacional. Docente do Centro Universitário Barão de Mauá Professor/Tutor da Faculdade de Educação São Luís e Universidade Federal de São Paulo. Docente da Rede Estadual de Ensino.

Recebido em: 09/03/2017 Aprovação fi

ReSUMO

A realidade atual vem afastando cada vez mais os adolescentes da prática da leitura. Com a grande diversidade de recursos midiáticos, que os levam a interessarem-se mais pelos bate-papos, games e vídeos disponíveis, com o restrito acesso à leitura no núcleo familiar e a falta de incentivo no meio escolar, nota-se pouco interesse por essa prática e, por consequência, dificuldades marcantes sentidas diretamente na escola: vocabulário precário, reduzido e informal; dificuldade de compreensão; erros ortográficos; poucas produções significativas dos alunos; conhecimentos restritos aos conteúdos escolares. Diante desse fato a presente pesquisa exploratória (questionário e entrevista), buscou compreender o uso e os hábitos de leitura entre alunos do $8^{\circ}$ ano de uma escola pública de Ensino Fundamental II, de Guariba - SP. Os resultados apontam para o desafio de despertar neste público a motivação para a prática e o prazer da leitura, fundamentais para o desenvolvimento do raciocínio, senso-crítico e da capacidade de interpretação.

PalaVRas-chave: Adolescente; Hábitos de Leitura; Ciberleitura.

READING PRACTICES: A STUDY WITH $8^{\mathrm{TH}}$ GRADE ELEMENTARY SCHOOL STUDENTS OF A PUBLIC SCHOOL IN GUARIBA-SP

\title{
AbSTRACT
}

Nowadays it is increasing the number of adolescents who are moving away from reading practices. With the great diversity of media resources, which lead them to become more interested in chats, games and videos available, with restricted access to reading in the family nucleus and the lack of incentive in the school environment, there is little interest in this practice and, consequently, significant difficulties are felt directly in school: precarious, reduced and informal vocabulary; difficulty in understanding; spelling errors; few students' significant text productions; knowledge restricted to school contents. Faced with this fact, the present exploratory research (questionnaire and interview) sought to understand the use and the reading habits of 8th grade elementary school students of a public school in Guariba - SP. The results point to the challenge of arousing in this public the motivation for the practice and pleasure of reading, fundamental for the development of reasoning, critical sense and interpreting capacity.

Keywords: Teenager; Reading habits; Cyber reading. 
INTRODUÇão

Atualmente, observa-se uma explosão tecnológica, que tem facilitado a vida de todos; antes, para termos acesso a um livro, era necessário dirigir-se à uma biblioteca; hoje, temos bibliotecas e acervos incríveis no computador, nos smartphones, porém não sabemos aproveitá-los. Os demais aplicativos têm tomado conta de um tempo, que antes era praticamente destinado à leitura. Vemos até mesmo pais e professores conectados diariamente no Whatsapp e Facebook, porém poucos se "conectam" a um livro. Vemos ainda, crianças que nem aprenderam a ler e escrever já ganharem um tablet ou celular, e não um livro impresso.

Falta o incentivo à leitura no ambiente familiar e atividades prazerosas no meio escolar, contribuindo para afastar crianças e adolescentes ainda mais dessa atividade extremamente importante para o desenvolvimento do raciocínio, senso-crítico e da capacidade de interpretação.

Neste cenário e com a chamada era digital, está cada vez mais difícil colocar-se como modelos leitores para as crianças e adolescentes e, consequentemente, difícil despertar neles o interesse pelo hábito de ler.

Para Moreira (2014), a forma como a criança é iniciada na leitura é fundamental para se tornar-ou não - um leitor competente e motivado. Todo esse processo começa no seio familiar onde encontramse os principais exemplos de conduta, tidos como modelos para toda vida, por serem espelhos de princípios e de comportamentos. Eé neste ambiente que se marca a construção da personalidade, das vontades, desejos e motivações.

Com relação à motivação da leitura entre as crianças, Moreira (2014, p.30) complementa:

A criança pode ser comparada a uma esponja insaciável e curiosa, atua por interacão com tudo e todos, com objetivo de reter a maior quantidade de informação, conhecimentos e experiências. Porém, para que não se experiências. Porém, para que não se
distancie, vai necessitar sempre de estímulos que a conduzam ao caminho da leitura porque, se assim não for, tempo vai tratar de direcionar a atenção da crinça para outros camin atenção mais frcen mais fúce de segur, como é o caso da televisa, que requer apenas vontade de ver, pouca aptidão e pouca concentração, e assim, se perde um leitor. Seguidamente, é necessário mostrar-lhe outras fontes de prazer, representando o ato de ler como natural, aprazível e espontâneo.

De acordo com Faria (1995), a mãe que lê para os filhos exerce influência fundamental no futuro leitor. É triste a constatação de que à medida que deixam de ser alunos, o índice de leitura diminua de maneira tão drástica. Assim, perde-se um dos principais modelos leitores, já que até a primeira infância, $o$ contato se dá apenas no ambiente familiar.

Em relação aos dados pesquisados e apontados em "Retratos da leitura no Brasil" Failla (2012), ao investigar os hábitos e a frequência da leitura entre estudantes de 5 e 12 anos, que correspondem a 16,8 $\%$ da amostra, notou-se que $45 \%$ delas leem sempre e sozinhas; $39 \%$ leem às vezes e $16 \%$ nunca leem. Nessa faixa etária encontra-se o número de crianças que responderam que outras pessoas leem para elas. Entre os mais citados, o professor tem lido mais do que a mãe, para os estudantes até 12 anos, conforme revelam os números: a mãe que sempre lê foi citada por $17 \%$ das crianças e a que lê às vezes por $43 \%$. O professor que lê sempre foi citado por $45 \%$ delas e, $41 \%$ citaram que o professor lê às vezes.

Em outra pesquisa realizado com três turmas do $6^{\circ}$ ano do Ensino Fundamental II, Góis (2012) observou que dos quinze alunos que participaram do questionário, apenas dois responderam que não gostam de ler, um respondeu que gosta um pouco e os outros doze afirmaram seu gosto e interesse pela leitura. Entretanto, posteriormente indagados sobre a compreensão daquilo que lê, diferentemente da questão anterior, as respostas não compreendem o que leem, seis afirmaram que compreendem mais ou menos e cinco afirmaram compreender toda leitura que fazem.

Neste sentido, é importante ressaltar o papel das instituições de ensino, juntamente com professores e equipe pedagógica, no sentido de resgata o valor da leitura como atividade prazerosa requisito para crescimento pessoal e profissional, propiciar momentos que possam despertar o gosto pela leitura, o amor ao livro e a consciência da importância de se adquirir o hábito de ler, visto que, por meio da leitura o ser humano consegue se transportar para o desconhecido, explorá-lo, vivenciar sentimentos e emoções que o cercam e acrescentar vida ao sabor da existência. Pode, então, realizar experiências que propiciem e solidifiquem conhecimentos significativos de seu processo de aprendizagem. Assim, oferece-se a leitura como instrumento chave para alcançar as competências necessárias a uma vida de qualidade, produtiva com realização.

Do hábito de leitura dependem outros elos no processo de educação: o jovem aprende a pesquisar, um texto, analisar, criticar, julgar e posicionar-se, além de ser capaz de adquirir domínio sobre a linguagem, autonomia e participação social. Ao estimular a leitura, o jovem torna-se também capaz de compre escola e o que acontece no mundo em geral.

De acordo com Yunes (1984, apud SANTOS 2006, p.31), o estímulo à leitura deve ser sistemático e uma meta prioritária em países em via de desenvolvimento, a busca por novas técnicas e estratégias de motivação para a leitura deve ser alvo de pesquisas que visem a aproximação do livro ao leitor.

Diante disso, o presente trabalho objetiva averiguar, através de pesquisa exploratória (questionário e entrevista), o uso e os hábitos de leitura entre um grupo de adolescentes do $8^{\circ}$ ano de uma escola pública de Ensino Fundamental II, no munícipio de Guariba - SP.

É importante ressaltar que a reflexão sobre o ensino e incentivo da leitura na escola é de extrema importância nos dias atuais, por isso, está pesquisa, vem ao encontro do trabalho desenvolvido por outros pesquisadores (GONCALVES, 2014; GÓIS, 2012) que buscaram por meio de análise com alunos do Ensino Fundamental (anos finais) desvendar e aprofundar essa temática não tão abordada como ocorre com as pesquisas voltadas aos anos iniciais do Ensino Fundamental.

\section{A importânCia da leitura}

Ler é ampliar visão de mundo e expandir horizontes, através de diferentes interpretações. De acordo com Lajolo (1993), ninguém nasce sabendo ler. Tal prática se aprende na medida em que se vive. Segundo ela, lemos para entender o mundo, para viver melhor e, simultaneamente, entendemos o mundo através da leitura, num círculo, numa prática nfinita. Ainda de acordo com a autora, a leitura é fonte de prazer e de sabedoria inesgotável. Em nossa cultura, quanto mais abrangente a concepção de mundo e de vida, mais imensamente se lê, numa espiral quase sem fim, que pode e deve começar na escola, mas não pode (nem costuma) encerrar-se nela.

Para Freire (1989), falar sobre a leitura e sua importância é algo complexo, já que esta é fundamental na vida das pessoas, pois é somente através dela que o ser humano conhece outras realidades, outros pensamentos e culturas, e consegue criar, recriar e reconstruir ideias. De acordo com ele, tal importância diz respeito a um processo que envolve uma compreensão crítica do ato de ler, que não se esgota na decodificação pura da palavra escrita ou da linguagem escrita, ou seja de modo mecânico puramente, mas que se antecipa e se alonga na inteligência do mundo.

A leitura tem sua importância não só ligada a textos escritos, segundo o autor acima citado, mas à leitura da realidade que rodeia o ser humano, ou seja, está ligada a tudo que faz parte da sua convivência, ela precede a leitura da palavra, daí que a posterior eitura desta não possa prescindir da continuidade da leitura daquela. Linguagem e realidade se prendem dinamicamente. A compreensão do texto a ser alcançada por sua leitura crítica implica a percepção 
das relações entre o texto e o contexto. Para o autor citado no parágrafo acima, a importância elo de ler e de escrever, no fundo indicotomizáveis, não se restringe à tabletes de conhecimentos que devessem ser engolidos pelos estudantes, como o conhecimento da regência verbal, da sintaxe de concordância, do problema da crase, do sinclitismo pronominal. Tudo isso, pelo contrário, era proposto à curiosidade dos alunos de maneira dinâmica e viva, no corpo mesmo de textos, ora de autores estudados, ora deles próprios, como objetos a serem desvelados e não como algo parado, cujo perfil se pudesse descrever. Para Freire (1989), educando não necessita memorizar mecanicamente a descrição do objeto, mas apreender a sua significação profunda, pois só assim torna-se capaz de saber, e automaticamente, irá memorizá-lo e fixá-lo. A memorização mecânica da descrição do elo não se constitui em conhecimento do objeto. Por isso é que a leitura de um texto, tomado como pura descrição de um objeto, e feita no sentido de memorizá-la, nem é real leitura, nem dela, portanto resulta o conhecimento do objeto de que o texto fala Failla (2012), aponta que ler é importante para que se tenha acesso ao conhecimento produzido por toda a humanidade, tendo em vista que o livro sempre foi o depositário de tudo o que o homem já pensou e criou; investigou e produziu como ciência, história e literatura. Com a internet, grande parte de todo esse 'conhecimento' encontra-se acessíve a todas as pessoas, na web.

Ainda de acordo com Failla (2012), necessitamos considerar a diferença entre informação conhecimento. A internet e as mídias em geral no possibilitam acesso a uma leitura utilitária que nos informa sobre acontecimentos, nos atualiza e ate nos prepara para algumas tarefas. Uma leitura crítica é a que desperta diferentes visões de mundo e da realidade e possibilita criar novos conhecimentos. A informação pasteurizada leva a uma sociedade homogênea, onde o pensar não cria, mas reproduz e cópia. Leva ao empobrecimento do que nos humanizou. Leva à alienação e à massificação.

Desse modo, conforme aponta Lajolo (1993, p.53), "leitor maduro é aquele para quem cada nova leitura desloca e altera o significado de tudo o que ele já leu, tornando mais profunda sua compreensão dos livros, das gentes e da vida". É através da leitura também que o ser humano exercita a sua imaginação e as suas emoções, por meio da literatura, que possibilita fantasias e desenvolve a imaginação do leitor.

\section{A escola, o jovem e a motivação para a} EITURA

Quem nunca se deparou com um professor que solicitava leitura em voz alta e ao final, observava como estava a leitura do educando? Ou aplicava um questionário, ou solicitava uma ficha de leitura, após cada realização de leitura de paradidático? Pois para a escola, a leitura continua sendo uma questão simples de ter ou não ter um bom desempenho escolar.

A escola, como entidade educativa, tem uma parcela de responsabilidade e culpa na falta de hábitos de leitura. Segundo Mafra, (2013), para o mundo da educação escolar, a leitura tende a permanecer uma prática excessivamente regrada, além do mais, é também por meio dela que a escola avalia se os alunos aprendem ou não, se gostam ou não de praticá-la, se leem bem ou não.

Existe um desencontro entre os interesses da escola e os dos adolescentes. Os estudos de Faria (1995), sinaliza a distância maciça entre os currículos escolares para a literatura e os sujeitosalvo deste currículo, isto é, os próprios leitoresalunos. De acordo com a pesquisadora citada, a leitura literária geralmente é feita por imposição do professor, sem considerar as tendências pessoais dos alunos, suas preferências e suas expectativas.

Além disso, Faria (1995) também afirma que, considerando os livros solicitados pelo professor, na própria escola, os adolescentes não têm espaço para expressar suas opiniões pessoais a respeito das leituras, uma vez que os professores costumam aplicar questionários padronizados e fechados, iguais para toda a turma, e passíveis de verificação rápida em termos de "certo" e "errado".

Portanto, nota-se que a leitura geralmente ocorre como forma de cobrança, para que se obtenha uma nota, ou para que se realize uma atividade pré-determinada pelo professor, e não como forma de prazer, de lazer, ou mesmo, como forma de expressão de sentimentos, de opiniões. Assim, tornando-se cada vez mais distante dessa geração.

Diante desse distanciamento entre o que é cobrado no ambiente escolar e o interesse dos adolescentes, Silva (1981, apud SANTOS, 2006 , p. 32) aponta:

E relevante o facto da leitura se ligar intimamente ao projeto educacional à própria existência do indivíduo (...) à proppra exis e pin do individuo (...) quanto mais a leitura fizer parte do quotidiano de cada um, haverá mais leitores realminte conscintes do que leem. Leitores afeitos ao prazer, sempre prontos para conhecerem outros mundos, outras ideias em benefício próprio.

E obrigatório à escola, em geral, resgatar o valor da leitura, se almejam um avanço educacional e formar ótimos adolescentes leitores, críticos e redatores

Lajolo (1993) aponta que a discussão sobre leitura, numa sociedade que pretende se democratizar, começa dizendo que os profissionais mais diretamente responsáveis pela iniciação na leitura devem ser bons leitores. Um professor precisa gostar de ler muito e se envolver com o que lê. E esse não é, infelizmente, o perfil comum do professor, atualmente.

Cabe à escola, e mais precisamente a quem lida diretamente com a aprendizagem da leitura, pelos educandos, reavaliar sua prática, percebendo que, assim como aponta Lajolo (1993), cada aluno-leitor, na individualidade de sua vida, vai entrelaçando o significado pessoal de suas leituras com outros significados e vai, ao longo da história do texto, fazendo suas recriações e reconstruções de significados.

Moreira (2014), aponta que pode se considera a escola como sendo o segundo lar de crianças e adolescentes, devido ao tempo e horas que estes passam no ambiente escolar. Esta instituição está intimamente ligada à vida dos alunos tendo diversos fatores em comum com o cotidiano deles. Desse modo, uma escola desconectada do mundo externo de seus alunos, de seus anseios, interesses e aflições, corre sério risco de ser ultrapassada e ficar para trás, contribuindo de maneira negativa e criando "inimigos da leitura". Diante disso, é importante haver discussões sobre assuntos diversos, do universo dos alunos, fazendo com que estes sintamse atraídos pelos hábitos de leitura, levando-os a progressivamente explorar outros temas, outros livros e anseiem conhecer novas histórias que os conduzam a universos desconhecidos. Para o professor ser um multiplicador de leitores, deve demonstrar aos adolescentes que a leitura não se resume a letras e papel, afirma Moreira (2014, p.37).

Porém, o que observa-se é que os adolescentes encontram-se perdidos, diante dos desafios vinculados à prática da leitura e a escola tem se ausentado no encaminhamento desta questão, aponta Lajolo (1993). Os adolescentes para os quais um mundo novo se apresenta a cada dia, associam a leitura a algo desinteressante que lhes é imposto e creem que seja algo anacrônico, preenchendolhes um tempo que poderia ser usufruído com ocupações compreendidas por eles como mais interessantes. Tem a necessidade de se fazerem diferentes, delimitarem o seu momento: seu jeito de corpo, trajes, linguajar e ações atestam isto. A autora observa também, que este descaso muitas vezes incomoda ao professor porque pode servir como sinalizador de seus impasses.

Há professores que relacionam a existência de maus leitores ao método de alfabetização ineficiente, contudo, de acordo com Silva (1998) a culpa desse fracasso não é da má alfabetização, mas, em parcela, do professor que faz uso indevido do método. Assim, não importa adotar métodos inovadores, se estes não forem bem explorados no contexto da sala de aula.

Ainda de acordo com Silva (1998), a escola deve alertar os professores para a estimulação do interesse dos alunos pela leitura não só literária, mas 
dos vários tipos. O assunto "livro" precisa ser um hábito dentro da sala de aula, fazendo-o de maneir informal e prazerosa, criando um ambiente adequado para o desenvolvimento do processo de leitura, e assim, estimulando também a leitura literária.

Moreira (2014), afirma que não implica dizer que o professor é o culpado pela falta de hábito de leitura, mas sim, que este será sempre um apoio importante na contribuição do aperfeiçoamento da técnica da leitura, nem sempre tornando esses adolescentes leitores ativos, porém, se esse apoio não for feito, esses adolescentes ficarão sempre desligados do hábito de ler. Vão continuar na escola, progredindo na leitura, mas sempre a correr o risco de perder o gosto e o hábito por essa atividade tão importante.

Em relação à literatura, há uma grande contradição no modo como esta lhes é apresentada, tornando-os mais desmotivados ainda para apreciála. De um lado, a literatura infanto-juvenil ora é apresentada na sua faceta pedagógica e moralizante, ora é associada à literatura de massa; de outro, num terceiro cenário, é vista como uma forma de iniciação à leitura, juntamente com outros textos. Esse desconforto mostra-se ainda maior quando estes conceitos se misturam. Na escola, a literatura é representada principalmente pelas coleções de paradidáticos e vista por eles, alunos, com um misto de estranhamento e apatia. O maior problema constata-se em não haver um trabalho com obras literárias de modo que a mesma seja vista como agradável. De acordo com Lajolo (1993), o contato com a literatura muitas vezes restringe-se à leitura e interpretação de fragmentos de textos retirados de livros didático. Segundo ela, o professor, com este material, geralmente não sente a necessidade de preparar aula, visto que tem um script de autoria alheia, composto de leitura jogralizada, testes de múltiplas escolhas, perguntas abertas ou semiabertas, reescrituras de textos, resumos comentados, entre outros, que levados para a sala de aula, não despertam interesses na "plateia", fazendo com que queixas de desatenção e rebeldi sejam reforçadas e comentadas no espaço externo ao da sala de aula.

É importante salientar, segundo Moreira (2014), o papel do professor como modelo ativo no processo de leitura, levando os alunos a perceberem que a leitura faz parte do dia-a-dia de todos nós, constituindo uma das ferramentas essenciais que conduz ao desenvolvimento de várias habilidades. Os profissionais envolvidos e responsáveis pela iniciação da leitura devem ser bons leitores, segundo a autora citada, bem como gostar muito de ler e envolvendo-se com aquilo que lê, visto que a leitura do professor é pré-requisito para a leitura do aluno. Desse modo, não basta apenas apontar teoria sobre a importância e os benefícios da leitura, mas sim haver profissionais capazes e competentes, que sintam eles próprios o prazer da leitura e possuam ampla visân ligação com a leitura, repassando-a a futuros leitores.

Nesse sentido, é urgente discutir-se o conceito de motivação, porque, segundo Lajolo (1993), é em obras literárias, pode se desfigurar completamente na prática escolar. Lajolo (1993, p.15) acrescenta, "ou o texto dá um sentido ao mundo, ou ele não tem sentido nenhum. E o mesmo se pode dizer de como leitor maduro, seja um importante mediador e modelo leitor para os adolescentes, se quiserem motivar esse público para o prazer da leitura. Lajolo (1993) aponta ainda que o professor de Português deve estar com a história da língua e com a literatura, não só da língua portuguesa, para saber explicá-las e consequentemente, integrar os alunos e habituálos à literatura. Em movimentos de ajustes sutis e constantes, a literatura gera comportamentos, atitudes, sentimentos, sensibilidades, valores, representações e imaginários coletivos e, é nesse sentido que a mesma torna-se fator importante na imagem que socialmente circula, ela constitui modalidade prazer são virtualmente ilimitados. A literatura é importante no currículo escolar, porque o cidadão precisa exercer sua cidadania, apossar-se da linguagem literária, alfabetizar-se nela, tornar-se seu usuário, mesmo que nunca vá escrever um livro.

LEITURA X INTERNET (CIBERLEITURA)

Discutir a respeito da leitura e da ciberleitura não seria possível sem antes abordar o advento da escrita, isso porque leitura e escrita estão articuladas, segundo Palma (2010). De acordo com a autora citada, desde os primórdios da história, o ser humano se deparou com o desafio de garantir que o conhecimento acumulado pudesse ser transmitido às demais gerações e servisse de base para novas descobertas e evoluções. O surgimento da escrita representou grande conquista para a humanidade, que passou a registrar todo o conhecimento adquirido, representando um marco na história, por preservar falas, ideias, fatos, ultrapassando limites de tempo e preservando a essência das variadas culturas.

Com o passar do tempo, alguns aspectos foram assumindo valores permanentes, possibilitando que mensagens escritas em determinado momento da história pudessem ser acessíveis para serem decodificadas e interpretadas por outros grupos sociais e contribuindo para o estudo contemporâneo de civilizações já extintas.

Contudo, com o avanço da escrita e leitura, na sociedade, apesar do grande número de pessoas já escolarizadas e com acesso a diversos tipos de textos escritos, apenas uma parcela da população tinha acesso às publicações com conhecimento científico, aponta Palma (2010). Ainda segundo ela com o desenvolvimento dos meios de comunicação de massa e das tecnologias digitais, que passaram a fazer parte do cotidiano de uma parte da população, foi a partir da segunda metade do século XX que observou-se grande avanço de uma cultura global, gerando, posteriormente, acesso irrestrito às bibliotecas virtuais, e consequentemente, trocas simbólicas entre pessoas dos mais diversos locais do planeta, por meio do mundo virtual, ou, ciberespaço. Essa nova cultura se manifesta pela presença constante de computadores em vários ambientes - familiar, escolar, profissional, de lazer, entre outros - que devido a facilidade de acesso articulação com outros meios digitais, como a telefonia móvel, jogos, etc., por exemplo, criam outra maneira de experienciar a sociedade e o mundo.

Ao contrário dos textos impressos, na web todas as informações são encontradas sistematicamente atualizadas e disponíveis aos usuários, na maioria das vezes sem gerar custos extras.

Ainda de acordo com Palma (2010), essa presença maciça dos computadores, faz com que, cada vez mais cedo, crianças comecem a interagir com todo esse aparato tecnológico e passem a ter seu desenvolvimento cognitivo e sensório-motor influenciados pelo mundo virtual. Diante disso, se a relação com o mundo se modifica, também se altera a relação com a leitura.

É preciso ainda deixar claro que a disponibilização dos textos online não significa o fim dos livros e materiais impressos, já que milhões de pessoas em todo o planeta desenvolvem uma relação especial com a textura do papel e a possibilidade de interagir com o autor, ainda que de maneira limitada, através de reflexões escritas nas bordas das páginas ou pedaços de papel colocados entre as páginas de um livro para identificar os trechos favoritos ou mais relevantes.

$\mathrm{O}$ fato de o texto ser apresentado na tela não muda nada, pois de acordo com Smith (1999, apud PALMA, 2010) a leitura online não descaracteriza os métodos tradicionais de leitura, pois segundo ele, as razões que fazem uma pessoa abrir um livro impresso, prazer, a informação, a identificação com a temática e pela experiência e hábito de leitura.

Além do mais, as qualidades do texto impresso podem ser trazidas com vantagens para os textos eletrônicos, articulando temáticas, autores clássicos e contemporâneos, diferentes linguagens, com leitura estabelecida pela lógica do leitor.

Sendo assim, a combinação de leitura impressa x ciberleitura não pode ser descartadas pela escola, especialmente pelos professores de Língua Portuguesa, visto que a ciberleitura abre um leque de novas possibilidades para o trabalho 
com a língua, a leitura e a literatura, substituindo atividades descontextualizadas e desprazerosas por outras mais criativas e interativas. É importante que os professores acompanhem o avanço tecnológico, e atentem-se para as diversas possibilidades de construção do conhecimento, que atendem a diferentes estilos de aprendizagem. O livro didático não é mais o único recurso acessível, é preciso apropriar-se das inúmeras outras possibilidades hoje disponíveis. Tanto os livros quanto as revistas, jornais, enciclopédias, $C D$-ROMs e sites da internet são fontes de informações úteis ao aprendizado. A internet é uma tecnologia que, pela novidade, amplia a motivação dos alunos à pesquisa. Contudo, é necessário que o professor assuma também um papel de leitor e pesquisador, para incentivar os alunos às mesmas práticas, levando-os a participar ativamente do processo de aprendizagem.

De acordo com Fernandes (2010), com a alvorada da internet, alterou-se totalmente o panorama da leitura, sendo preciso correr atrás do leitor, entendê-lo para tê-lo. Além do mais, é necessário direcionar esse público, para essa explosão de novas possibilidades, pois, do contrário, a visão irrealista de que livros são objetos ultrapassados se manterá Failla (2012, p.24) acrescenta:

Não podemos deixar de considerar complexidade do momento em que vivemos. Se, por um lado, anda deparamos com nímeros expressivos de analfabetos absolutos ou funcion. Basil e descobimos que $50 \%$ dos no Brasil, e descobrios our que $50 \%$ dos brasileiros não lerann nenhum livo nos três meses anteriores à pesquisa Retratos da leitura no Brasil; por outro, encontramos jovens com nível superior que não têm interesse em ler livros por acreditarem que seja um objeto ultrapassado pela tecnologia da informação. E, pior, que se satisfazem em ter acesso a milhares de informacõ em criticá-las ou em refletir sobre sers significados ou intenc̃ Jovens a quem nas foi possibilite Jovens a quem não foi possibilitado sonhar com castelos; temer monstros ou acreditar que o bem sempre vence o mal.

A pesquisa apontada pela edição de "Retratos da leitura no Brasil", Failla (2012), mostra também uma investigação sobre o perfil do leitor de livros digitais e revela que, entre os usuários de internet, $7 \%$ informaram que já baixaram ou leram livros pela internet. Já ouviram falar delivros digitais, 18 entrevistados e entre eles, $17 \%$ informaram que já leram algum livro no computador e $1 \%$ no celular. É preciso pensar em políticas públicas e ações efetivas, em um cenário tão complexo e de grande desafio. Tarefa para toda a sociedade, visto que a leitura e, atualmente a ciberleitura, é habilidade essencial para o acesso ao conhecimento, à cultura e para uma formação plena e humanizada.

\section{Prochdigentos Metodológicos}

Foram convidados 32 alunos com idades entre 13 e 14 anos, do Ensino Fundamental II, matriculados no $8^{\circ}$ ano de uma Escola Municipal da cidade de Guariba - SP, para participar do estudo. A escola está localizada num bairro de classe média baixa e oferece ensino de $6^{\circ}$ a $9^{\circ}$ ano. A escolha desta escola se deu por conta de a mesma ser classificada como uma das melhores escolas públicas da cidade, em termos de aprendizagem e média nas avaliações externas.

A coleta de dados deu-se por meio de um questionário composto por questões referentes aos hábitos e frequencia de leitura, tambem questões abertas, como: "Para você, o que é ler?"; "Você acha que ler é importante?". Um total de 32 questionários foram respondidos de modo presencial em sala de aula.

\section{RESUltados E Discussão}

Observando os questionários recebidos, a primeira constatação é evidente e até mesmo previsível: nem todos adolescentes se interessam por leitura. Relataram gostarem de ler 66\% (21 alunos) entrevistados e 34\% (11 alunos) declararam não gostarem desse hábito (Figura 1).

Entre os que não gostam da prática de leitura,
Figura 1 - Porcentagem de alunos que gostam de ler.

m

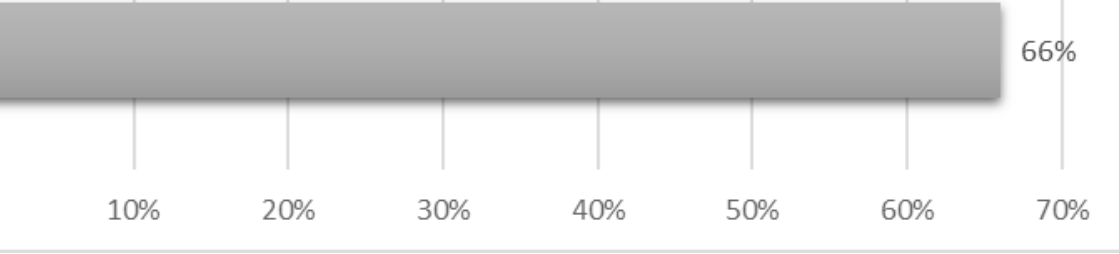

Fonte: Elaborado pelos autores.

Figura 2 - Motivos do desinteresse pela leitura, sinalizados pelos entrevistados.

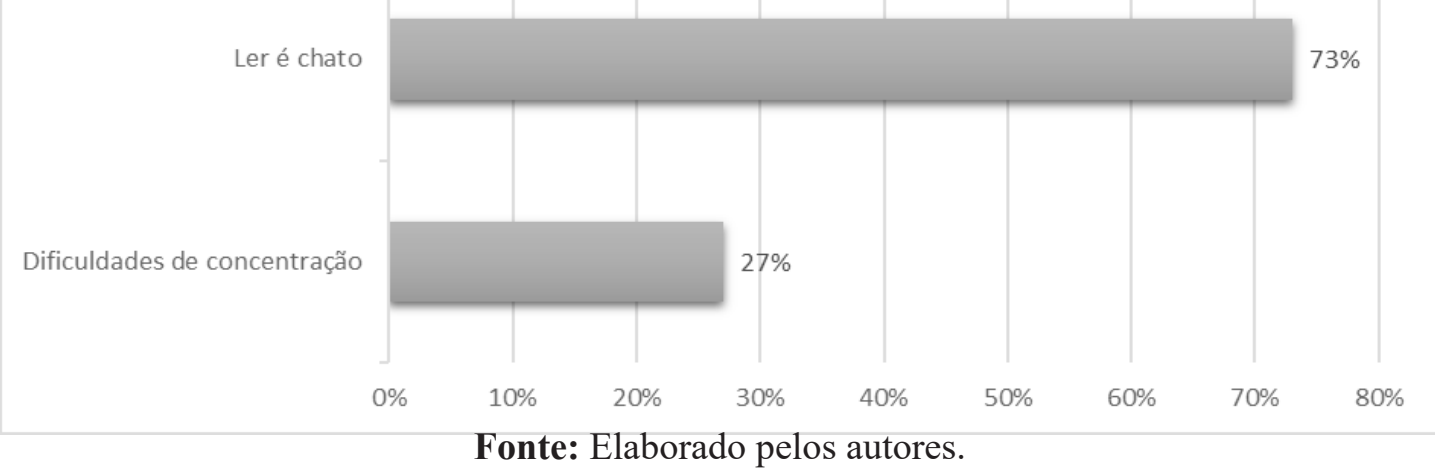

Figura 3 - Como os entrevistados preferem passar o tempo livre.

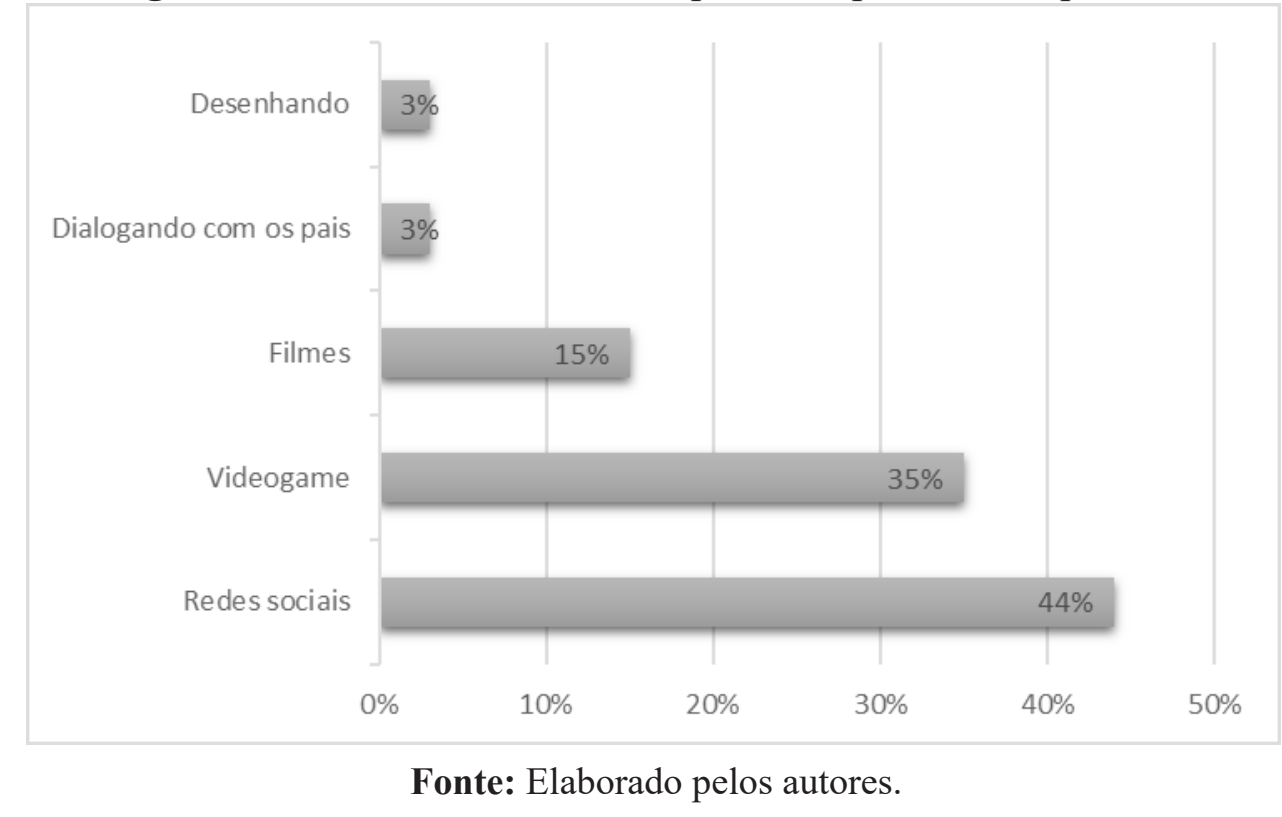


duas respostas sinalizaram os motivos desse como absolutamente normal encontrar no grupo

desinteresse: a mais preocupante ( $73 \%$ - 23 alunos) de entrevistados atitudes como as demonstradas é a concepção, pel chato" e 27\% (9 alunos) disseram que apresentam "dificuldades de concentração", conforme aponta Figura 2.

Assim, possivelmente entendem que ler é algo necessariamente sério e regrado, desse modo, visto como próximo a uma atividade escolar, na qual cobram-se deles um rendimento em forma de notas, afastando a imagem de que a leitura possa ser considerada uma oportunidade de entretenimento e lazer, ou de aprendizagem a partir da diversão da imaginação, por exemplo. Sobre esse aspecto (diversão e entretenimento), 44\% (14 alunos) relataram que preferem passar seu tempo livre mexendo nas redes sociais (Facebook, Instagram, Whatsapp, entre outros); $35 \%$ (11 alunos) relataram que preferem passar seu tempo livre jogando videogame; $15 \%$ (5 alunos) assistindo filmes; $3 \%$ ( 1 aluno) conversando com os pais e 3\% ( 1 aluno) desenhando (Figura 3).

Percebe-se o domínio das mídias na vida dos entrevistados, possibilitando-os experienciar o mundo sob uma nova perspectiva, tecnológica, reforçando ainda mais a importância de uma modificação também em relação à leitura, se quisermos ganhar novos leitores, tendo em vista que nenhum entrevistado referiu que prefere passar suas horas vagas lendo livros, embora $65 \%$ referiram que gostam de leitura. Dessa forma, é possível entender que, mesmo a maioria dos adolescentes demonstrando que gostam de leitura $(65 \%)$, não o fazem, pois não associam tal prática com diversão ou entretenimento, sinalizando o perfil de desinteresse, bem como de falta de motivação e de modelos positivos, que envolvam a leitura como forma de obter prazer.

Considerando que são diversos os fatores que levam um jovem a não gostar de leitura (como falta de incentivo e hábito no ambiente familiar e escolar, outros interesses individuais, etc.), entendemos

as respostas acima

Observa-se ainda alguns dados bastante variados nas respostas. Quanto à quantidade de livro lidos por ano, apontaram: nenhum livro - 36\% (12 alunos); 1 a $3-42 \%$ (13 alunos); 4 a $6-19 \%$ (6 (annos); mais de $10-3 \%$ (1 aluno), conforme aponta Figura 4.

Esses dados, vem ao encontro da Pesquisa Retratos da Leitura no Brasil (2016) ${ }^{1}$, realizada pelo Ibope por encomenda do Instituto Pró-Livro que indica que o brasileiro lê apenas 4,96 livros por lidos por vontade própria (cf. Figura 6).

Em relação à frequência com que realizam atividades de leitura, 9\% (3 alunos) dos alunos declararam que leem todos os dias e $31 \%(10$ alunos) que leem quase todos os dias, ocorreram respostas declarando ler uma vez por semana: $16 \%$ (5 alunos); uma vez ao mês: $6 \%$ (2 alunos); uma vez ao ano: 3\% (1 aluno); raramente: 16\% (5 alunos) quando obrigatório: 19\% (6 alunos) (Figura 5).

Por mais que a frequência de leitura varie, resultando em quantias bastante discrepantes, quando olhamos para o grupo como um todo, podemos observar alguns pontos de confluência no perfil destes alunos, a partir das respostas dadas para as outras questões, porém, com contradições; por exemplo, quando $31 \%$ (10 alunos) referem que leem quase todos os dias, mas a média de livros que apontaram ler ao ano, não corresponderem à frequência com que realizam tal atividade, reforçando assim, a ideia de que os adolescentes encontram-se perdidos, em relação aos hábitos de leitura, como aponta Lajolo (1993) e que até realizam atividades de leitura com frequência, mas por obrigação, possivelmente nas atividades escolares.

Com base nos modelos leitores que os influenciam, apontaram que não são influenciados por ninguém: 44\% (14 alunos); são influenciados
Figura 4 - Porcentagem de livros lidos ao ano.

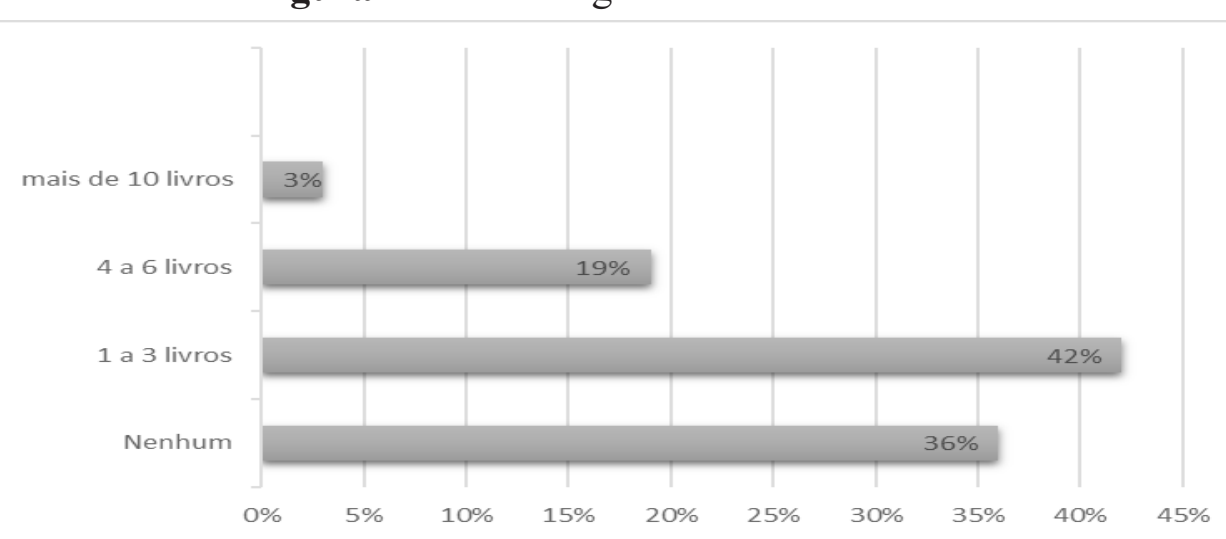

Fonte: Elaborado pelos autores

Figura 5 - Porcentagem da frequência com que realizam atividades de leitura

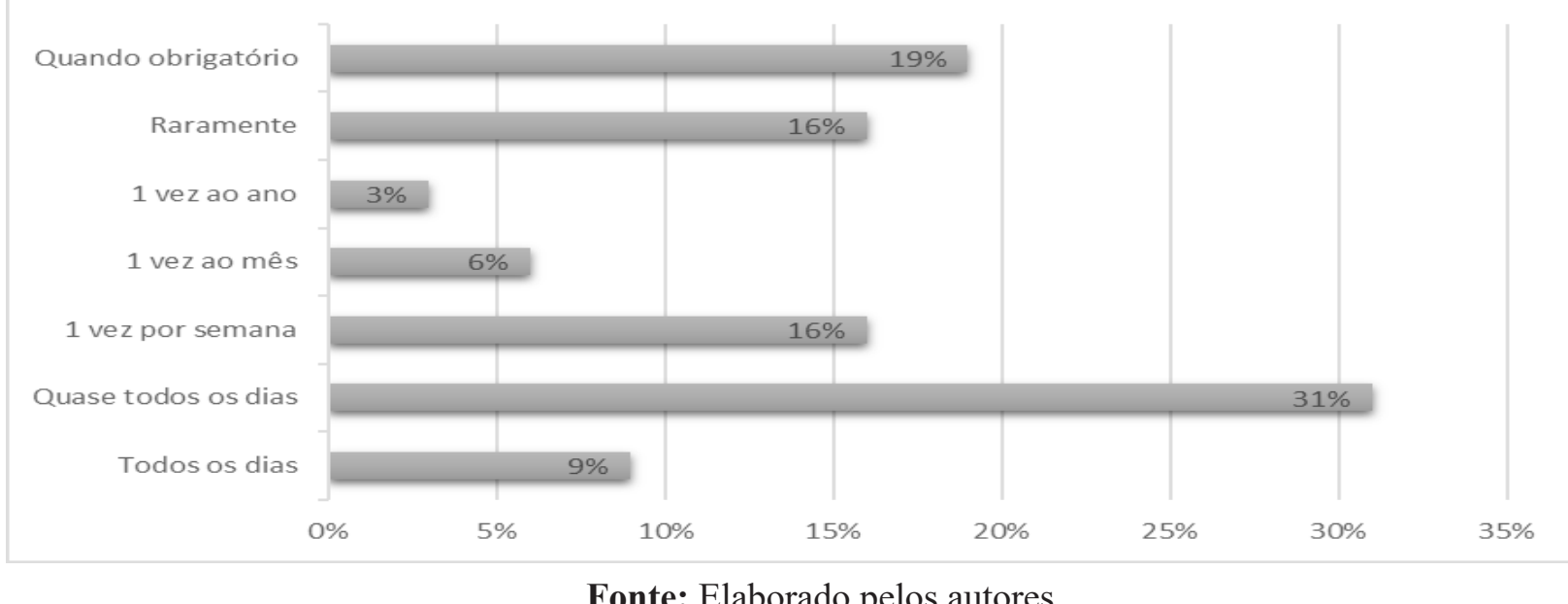

Fonte: Elaborado pelos autores.

Figura 6 - Modelos leitores que os influenciam nas atividades leitoras.

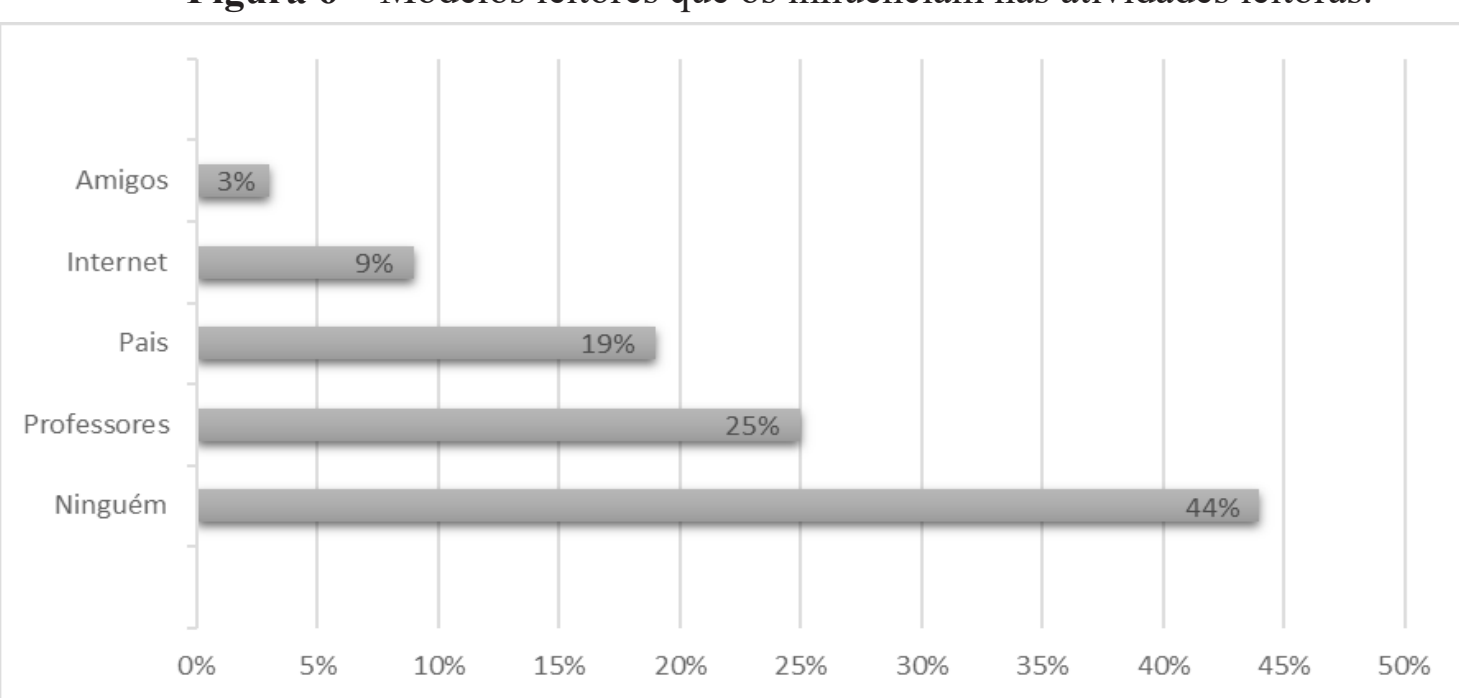

Fonte: Elaborado pelos autores. 
Figura 7 - Influenciados dos professores em relação a leitura no ambiente escolar.

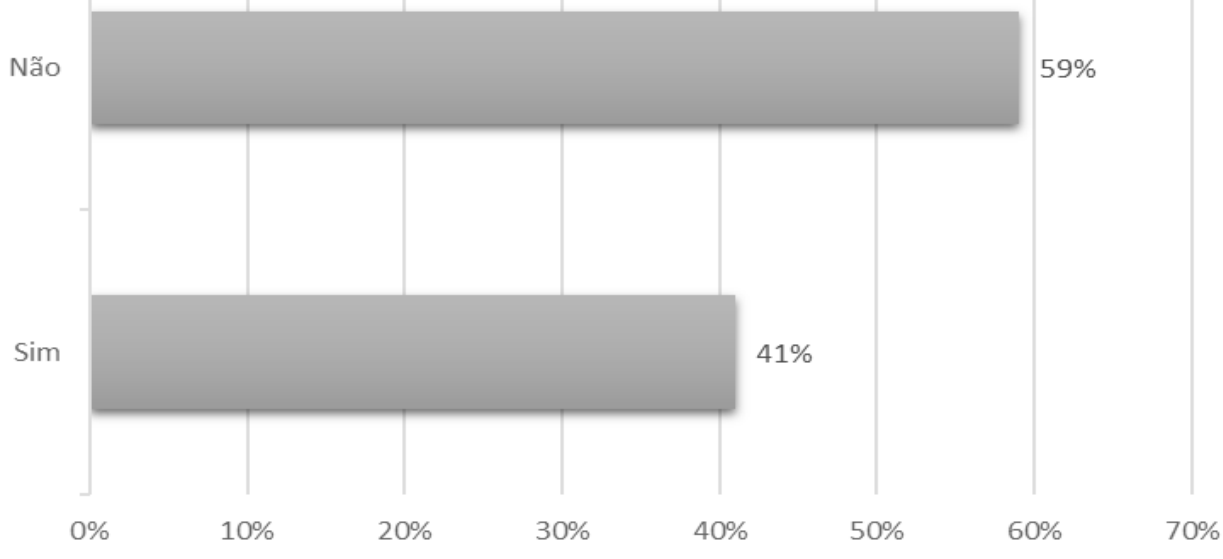

Fonte: Elaborado pelos autores

Figura 8 - Porcentagem que já leu algum livro no computador

Não

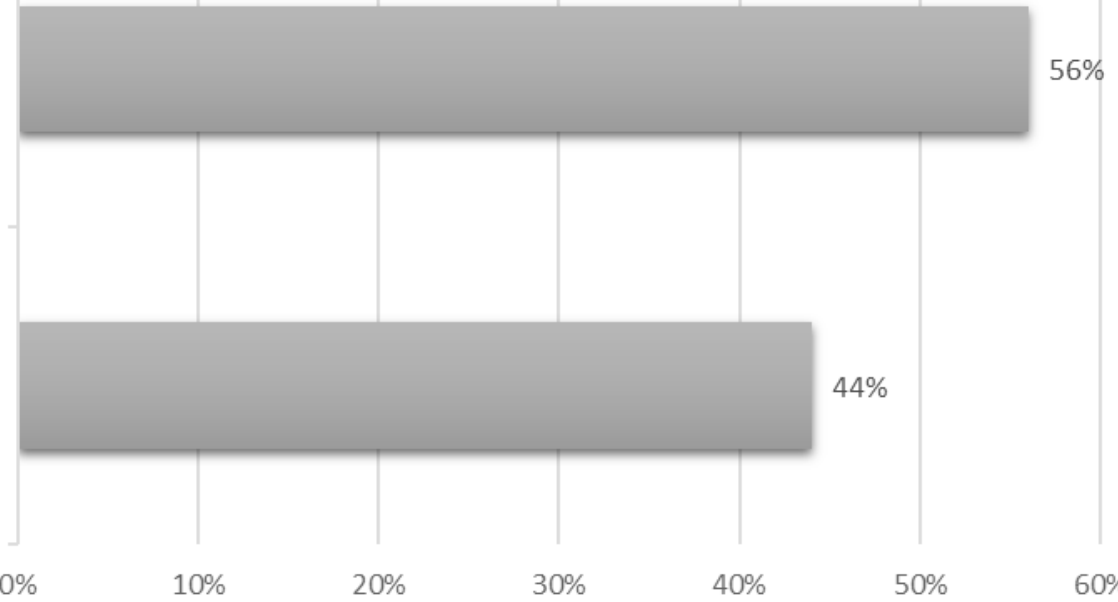

Fonte: Elaborado pelos autores.

por professores: $25 \%$ (8 alunos); pelos pais: $19 \%$ ler. Sendo que, apenas $37 \%$ (12 alunos) disseram ter (6 alunos), internet: 9\% (3 alunos), amigos: 3\% (1 algum familiar que tenha tal hábito, os mais citados aluno) (Figura 6). Contudo ao serem indagados, foram os irmãos (19\% - 6 alunos).

$47 \%$ (15 alunos) afirmaram que os pais costumam lhes comprar livros, e 53\% (17 alunos) nunca ganharam um livro dos pais. Ainda em relação às influencias no ambiente familiar, $28 \%$ (9 alunos) relataram que já viram os pais lendo algum livro; $\mathrm{e}$ $72 \%$ (23 alunos) nunca viram os pais com hábito de

Com base na Figura 6, observa-se que a maioria dos entrevistados não recebe influência alguma para a prática da leitura, sendo que, quando procuram o fazem, em sua maior parte, por interesse próprio.

Ao analisar as influências recebidas no ambiente escolar (Figura 7), apenas 41\% (13 alunos) dos alunos relataram que já ouviram seus professores comentarem sobre algum livro que estejam lendo atualmente, ou incentivarem a prática de leitura. A maioria também, referiu que nunca leu algum livro no computador ou smartphone: 56\% (17 alunos) dos entrevistados (Figura 8).

Comparando com a Pesquisa Retratos da Leitura no Brasil (INSTITUTO PRÓ-LIVRO, 2016) para $67 \%$ da população, não houve uma pessoa que incentivasse (influenciasse) a leitura em sua trajetória, mas dos 33\% que tiveram alguma influência, a mãe, ou representante do sexo feminino, foi a principal responsável $(11 \%)$ seguida pelo professor $(7 \%)$

Também conforme apontou a Pesquisa Retratos da Leitura no Brasil (INSTITUTO PRO-LIVRO, 2016) a livraria física é o local preferido dos entrevistados para comprar livros (44\%), seguida por bancas de jornal e revista (19\%), livrarias online $(15 \%)$, igrejas e outros espaços religiosos $(9 \%)$, sebos $(8 \%)$, escola (7\%), supermercados ou lojas de departamentos $(7 \%)$, bienais ou feiras de livros $(6 \%)$, na rua, com vendedores ambulantes $(5 \%)$, outros sites da internet (4\%), em casa ou no local de trabalho, com vendedores "porta a porta" $(3 \%)$, outros locais (6\%) e não sabe/não respondeu (7\%).

Ao solicitar que escrevessem suas opiniões sobre o significado de ler, apareceram respostas como "ler é importante para exercitar a mente, para aprender", "Ler é conhecer as histórias, saber o que acontece com o personagem", "Ler é para ajudar no futuro, ter um trabalho", "Ler é viajar, imaginar, é lazer". Apenas 3\% (1 aluno) referiu não saber explicar o que era leitura. Já ao questioná-los sobre a importância do ato de ler, 94\% (30 alunos) referiram que acham muito importante e, apenas 6\% (2 alunos) disseram que não.

Diante dos resultados encontrados, é possível apontar que os adolescentes sabem da importância do ato de ler, até referem gostar de ler, porém, não conseguem fazer associações com a leitura por prazer. De acordo com Fernandes (2010), a escola, pelo que tudo indica, ao bater na tecla da leitura crítica, subentende-se que, para chegar a esse estágio, o aluno leitor precisa seguir etapas, digerir autores, acompanhar escolas, responder provas e questões, ou seja, tem de matar o prazer da leitura para conquistar o conhecimento. Com a leitura sem prazer estético, o que sobra é a leitura de penitência, de cobranças e, consequentemente, leitura "chata", conforme referiram a maioria dos entrevistados que não apreciam tal atividade.

É preciso uma postura menos unilateral por parte dos professores, é necessário renunciar à figura do aluno como tábula rasa e converter-se a um outro campo de experiências mais atrativas e em acordo com os interesses desse público. Ter que lidar com esses adolescentes em transformação, que são os leitores, e ao mesmo tempo orientá-los, de modo a garantir a transmissão do conhecimento é tarefa árdua.

\section{CONSIDERações FINAIS}

Não há dúvidas de que a escola, principalmente através da figura do professor, tem grandiosa importância na formação do leitor e na motivação para a leitura, porém não somente esses. A pesquisa apontou os principais agentes motivadores para a leitura e também a ausência destes na maioria dos casos, o que levanta para uma transformação da escola, no tocante ao estímulo e incentivo à leitura. Neste sentido, a obra "Retratos da Leitura no Brasil", aponta propostas como a incrementação de programas para bibliotecas, formação de professores mediadores, práticas leitoras em aula entre outras que promovem as habilidades leitura e escritora

Ainda, como podemos observar pelos dados da pesquisa apresentada, muitos são os desafios no âmbito da leitura e em relação aos adolescentes de hoje; muitos também são os caminhos. O que não se pode deixar de lado é a capacidade de torná-los cidadãos críticos, com seus direitos respeitados. Assim, é necessário, principalmente à escola, mudar paradigmas, abrindo espaço para concepcões peitura, que, de acordo com Lajolo (1993), privilegiem a reflexão sobre a natureza e o percurso social da leitura, deixando em plano secundário 
metodologias e estratégias que costumam ser, na FACES. Brasília, 2012.

prática, ineficientes para despertar nos adolescentes o gosto pela leitura. Só assim poderemos responder a um mundo que se transforma cada vez mais rápido, com tanta evolução e desafios

Finaliza-se esse estudo na esperança de que as discussões e dados apresentados possam colaborar para um melhor entendimento do cenário da leitura de adolescentes, a partir de um grupo focal específico, bem como ter contribuído com ideias relevantes para harmonizar as relações entre os interesses dos alunos e os da escola.

\section{REFERÊNCIAS}

FAILLA, Z. (Org.). Retratos da leitura no Brasil 3. 3.ed. São Paulo: Instituto Pró-livro/ Imprensa Oficial, 2012.

FARIA, M. A. O que pensam os adolescentes das histórias que lêem? Comunicação e Educacãa São Paulo, V. 3, n.3, p.30-35, mai /ago.,1995

FERNANDES, J.C. Apropriação da leitura crítica. In: BORGES, A. G. S.; ASSAGRA, A. G.; ALDA, C. G. L. de. Leitura: o mundo além das palavras/ Instituto RPC. 1.ed. Curitiba: Instituto RPC, 2010. p.33-48.

FREIRE, P. A Importância do Ato de Ler: en três artigos que se completam. 23.ed. São Paulo: Autores Associados; Cortez, 1989.

INSTITUTO PRÓ-LIVRO. Retratos da Leitura no Brasil. 4.ed. São Paulo: Instituto Pró-livro, 2016. Disponível em: http://prolivro.org.br/home/ images/2016/Pesquisa Retratos da Leitura no Brasil_-_2015.pdf. Acesso em: 28 abr. 2017.

GÓIS, Luciana Ribeiro dos Santos. O ensino da leitura nas escolas de ensino fundamental II 2012, 52 f. Monografia (Graduação em Letras) Centro Universitário de Brasília - UniCEUB. Faculdade de Ciências da Educação e Saúde -
GONÇALVES, Maria Euza Silva. Importância da leitura no Ensino Fundamental.

2014, 57 fls. Monografia (Especialização

Fundamentos da Educação: Práticas Pedagógicas Interdisciplinares). Universidade Estadual da

Paraíba. Campina Grande/PB. 2014

LAJOLO, M. Do mundo da leitura para a leitura do mundo. São Paulo: Ática, 1993.

\section{MAFRA, N. D. F. Leituras à revelia da escola} [livro eletrônico]. Londrina: Eduel, 2013. Disponível em: http://www.uel.br/editora/portal/ pages/livrosdigitais-gratuitos.php. Acesso em: 03 dez.2016

MOREIRA, I. S. P. Motivação para a leitura. Santa Maria, 2014. Tese (Mestrado em Educação Pré-Escolar e $1^{\circ}$ Ciclo do Básico) - Instituto Superior Politécnico Gaya.

PALMA, M.S. Di. Ciberleitura. In: BORGES, A. G. S.; ASSAGRA, A. G.; ALDA, C. G. L. de Leitura: o mundo além das palavras/ Instituto RPC. 1.ed. Curitiba: Instituto RPC, 2010. p.161175.

SANTOS, M.V. Machado dos. A leitura como prática cotidiana e motivacional: da infância ao crescimento intelectual e discernimento crítico. Revista ABC: Biblioteconomia em Santa Catarina. Florianópolis, v. 11, n.1, p.29-37, jan./ jul., 2006.

\section{SILVA, E.T. Elementos de Pedagogia da}

leitura. 3.ed. São Paulo: Martins Fontes, 1998.
SILVA, Claudionor Renato da. - Docente e pesquisador do Curso de Pedagogia e Matemática EaD UFT/Arraias.

\section{ReSUMO}

As produções no campo da educação sobre a orientação científica docente do Trabalho de Conclusão de Curso (TCC) vêm aumentando, consideravelmente e se concentram nas áreas da Educação a Distância e Educação em Ciências e Matemática. Contudo, estas produções, no seu conjunto, exigem uma organização e delineamento urgentes referente ao rigor científico da produção de conhecimento; necessita-se de uma epistemologia sobre a orientação docente. Na tentativa de acrescentar um item reflexivo no campo educacional, este ensaio se debruça sobre o tema, tecendo considerações sobre a orientação docente do TCC na formação inicial de pedagogos(as), privilegiando algumas linhas conceituais e teóricas: 1) teoria da afetividade na orientação; 2) teoria motivacional. Com o uso do método bibliográfico atende-se à seguinte pergunta de pesquisa: de que forma algumas linhas conceituais vêm apontando a articulação entre orientação docente, TCC e pesquisa educacional, em cursos de pedagogia e como elas se apresentam como recursos sadios e produtivos na relação orientador(a)/orientando? Ao se apresentarem as duas linhas teóricas se propõem alternativas à orientação docente e à produção dos orientandos(as). Finaliza-se o ensaio com a reflexão sobre o que se configura um "bom" TCC e o aspecto da publicização, e, para isto, se apresenta a Teoria das Restrições como modelo de gestão da produção do TCC em cursos de pedagogia para se atingir a práxis educativa com a transformação da realidade, pela pesquisa.

Palavras-chave: Orientação docente; TCC; Pedagogia.

\section{PEDAgOgues' COURSE CONCLUSION PAPER: ORIENTATION AND MODELS OF GUIDANCE THEORY}

AbSTRACT

The productions in the field of education on the teaching scientific guidance of Course Conclusion Paper (TCC, in Brazil) have increased considerably and focus on areas of Distance Education and Education in Science and Mathematics. However, these productions, as a whole, require an organization and urgent design regarding the scientific rigor of knowledge production. It is necessary an epistemology on teacher guidance. In an attempt to add a reflective item to the educational field, this essay focuses on the subject, bringing considerations on the teaching orientation of the TCC in the initial training of teachers, privileging some conceptual and theoretical lines: 1) theory of affectivity in guidance; 2) motivational theory. Using a bibliographical method we answer the following research question: how have some conceptual lines indicated a link between teacher guidance, TCC and educational research in pedagogy courses and how they present themselves as healthy and productive resources in the mentor/mentee relationships? When presenting the two theoretical lines, we propose alternatives to teacher orientation and to the production of mentees. The essay ends with a reflection about what is considered a "good" TCC and the appearance of the TCC publicity and, for this, we propose the Theory of Restrictions as a model of production management of TCC in pedagogy courses to achieve the educational praxis with the transformation of reality, by means of research.

VoL. 20, N.1, JuLно 201

Revista Brasileira Multidisciplinar - ReBraM 